\title{
Emphysema and airway obstruction in non-smoking South African gold miners with long exposure to silica dust
}

\author{
Eva Hnizdo, Gerhard K Sluis-Cremer, Eugene Baskind, Jill Murray
}

\begin{abstract}
Objective-Occupational exposure to silica dust is associated with significant impairment of lung function. The present study investigates which pathological changes in the lung are associated with impairment of lung function in silica dust exposed workers who were life-long nonsmokers.
\end{abstract}

Methods-242 South African white gold miners who were lifelong non-smokers and who had a necropsy at death were studied. The pathological features identified at necropsy were the degree and type of emphysema, the presence of airway disease, and the degree of silicosis in the lung parenchyma and pleura. These features were related to lung function tests done a few years before death, to type of impairment (obstructive or restrictive), and to cumulative silica dust exposure.

Results-The degree of emphysema found at necropsy was not associated with a statistically significant impairment of lung function or with dust exposure. The degree of silicosis in the lung parenchyma and the large airways disease (based on mucus gland hyperplasia) were associated with a statistically significant impairment of lung function. The large airway disease was, however, not positively associated with dust exposure or silicosis. In miners with a moderate or a higher degree of limitation of airflow the main findings were silicosis, heart disease, and obesity. The presence of small airways disease could not be established from the necropsy material.

Conclusion-The results indicate that the level of exposure to silica dust to which these miners were exposed, without a confounding effect of tobacco smoking, is not associated with a degree of emphysema that would cause a statistically significant impairment of lung function. Silicosis of the lung parenchyma was associated with loss of lung function. Other factors that may play a part in impairment of lung function in these miners are obesity and heart disease.

(Occup Environ Med 1994;51:557-563)

It has been shown in experimental animals ${ }^{1}$ and also in humans ${ }^{2-4}$ that exposure to silica or mineral dust containing a large percentage of silica can result in pathological changes in the lung parenchyma other than silicosis and that these changes result in impairment of lung function. The changes are emphysema, ${ }^{56}$ thickening of small airways, ${ }^{1}$ and pronounced fibrosis and pigmentation of the respiratory bronchioles. $^{2}$

It is uncertain whether the impairment of lung function in workers exposed to silica dust is due to the change in the alveoli (emphysema) or in the small airways. The American Thoracic Society suggests that in subjects at risk of developing chronic obstructive pulmonary disease (COPD), pathological changes in the peripheral airways precede the development of emphysema and that these changes on their own, without emphysema, may be responsible for subtle abnormalities in pulmonary function tests that are not associated with physical impairment. ${ }^{7}$

Workers in South African gold mines are exposed to low levels of respirable dust $(\approx 0.4$ $\mathrm{mg} / \mathrm{m}^{3}$ ) containing a high percentage of crystalline silica $(\approx 30 \%)$. Epidemiological studies have shown that exposure to silica dust is positively associated with the degree of emphysema, assessed in paper mounted lung sections obtained at necropsy, ${ }^{56}$ but that the estimated effect of silica dust relative to that of smoking is of smaller magnitude. ${ }^{6}$ It has also been shown that the centriacinar type of emphysema occurred mainly in men who smoked, whereas in the non-smokers there was a small degree of the panacinar type of emphysema. ${ }^{6}$ Other studies have found a statistically significant association between exposure to silica dust and loss of lung function $\left(\mathrm{FEV}_{1}, \mathrm{FVC}, \mathrm{FEF}_{25-75 \%}\right)$ in smoking and non-smoking gold miners. ${ }^{48}$ In white gold miners, the impact of tobacco smoking and the combined effect of tobacco smoking and silica dust were found to be the most important risk factors contributing to disability and mortality from COPD. ${ }^{8}$

The purpose of the present study was to investigate further which pathological changes found in workers exposed to silica dust are mainly responsible for the loss of lung function. As the impact of tobacco smoking on COPD has been shown to be substantially greater than that of silica dust, only gold miners who were lifelong non-smokers were included in this study. In particular, answers to two questions were sought. Firstly, in nonsmoking gold miners with airflow limitation, which of the following can be implicated: silicosis, emphysema, airway disease, or other factors? Secondly, does the assessment of airway disease, as made at necropsy on South 
African gold miners, (bronchitis, based on mucus gland hyperplasia, and bronchiolitis, based on goblet cells metaplasia) reflect lung function impairment associated with exposure to silica dust? The morphological changes examined were (a) emphysema (type and degree); (b) small airways disease (goblet cells metaplasia); (c) large airways disease (mucus cell hyperplasia); and (d) the presence and degree of silicosis in lung parenchyma and hilar glands.

Black gold miners, who have much lower tobacco consumption, could not be used in this study as they have a substantially lower necropsy rate and less reliable exposure records than the white miners.

\section{Materials and methods}

SELECTION OF STUDY SUBJECTS

By South African law it is obligatory for an attending physician to remove the cardiorespiratory organs of a deceased subject who is known or suspected of having worked in mines and to send them for an examination to the Medical Bureau for Occupational Diseases (MBOD), provided that the next of kin agrees. If the subject dies within a $100 \mathrm{~km}$ radius of Johannesburg, the whole body is sent for a full or partial necropsy. The pathological examinations are performed at the National Centre for Occupational Diseases (NCOH) according to a standard method set down by the Pneumoconiosis Act of 1956 . The results of the pathological examination of the lungs are used for compensation purposes. Since 1974, all the necropsy records have been stored on a computerised database (PATHAUT).

The study subjects were selected from PATHAUT if they fulfilled the following criteria: (a) full or partial necropsy examination during the years from 1974 to 1990 ; $(b)$ white miners with predominantly gold mining exposure (those with asbestos exposure or more than two years of mining on mines other than gold mines were excluded); (c) age at death 45 years or more; $(d)$ a lifelong non-smoker. Of the 16724 necropsies performed during 1974-90 on white miners, 5681 were done on miners who had predominantly gold mining exposure and whose lungs were inflated at necropsy. Of these, 712 were coded on PATHAUT as non-smokers and 510 as of unknown smoking habits. The MBOD medical files of all these miners were examined to check their smoking history; smoking habits are recorded annually since 1960 . At the end only 242 miners met the criteria and remained

Table 1 Agreement between study scores and original NCOH scores for the degree of emphysema

\begin{tabular}{llllll}
\hline $\begin{array}{l}\text { Study } \\
\text { scores } \\
(\%)\end{array}$ & \multicolumn{2}{l}{ NCOH pathologists } & & \\
\cline { 2 - 5 } & None & Insignificant & Moderate & Marked & Total \\
\hline$<10$ & 125 & 31 & 1 & 0 & 157 \\
$10-34$ & 28 & 50 & 3 & 0 & 81 \\
$35-64$ & 0 & 2 & 2 & 0 & 4 \\
$\geqslant 65$ & 0 & 0 & 0 & 0 & 0 \\
Total & 153 & 83 & 6 & 0 & 242 \\
\hline
\end{tabular}

in the study. Most men excluded because of missing smoking data stopped their mining exposure before 1960 . In other excluded miners, the medical file indicated past smoking.

About $86 \%$ of deceased white gold miners have a necropsy at $\mathrm{NCOH}$. To establish whether non-smokers have the same necropsy rate as other miners, we have examined the necropsy rates for non-smokers included in a 17 year mortality follow up study done on 2260 gold miners. ${ }^{8}$ Of the 239 non-smokers, 69 died and $87 \%$ of these had a necropsy at $\mathrm{NCOH}$, but not all had inflated lungs. The necropsy rates were $77 \%, 94 \%$, and $63 \%$ in those with no compensation, first degree, and second degree compensation in life, respectively. In gold miners compensable diseases are pneumoconiosis, chronic obstructive pulmonary disease (COPD), tuberculosis, and progressive systemic sclerosis. The second degree is usually awarded to miners who have pneumoconiosis and COPD). Thus the degree of compensation in life affects to some extent whether a miner has a necropsy.

\section{ASSESSMENT OF EMPHYSEMA}

At full or partial necropsy the lungs are inflated with formaldehyde and paper mounted whole lung sections are made from one lung, usually the right one, with the Gough-Wentworth technique. The degree of emphysema is assessed for compensation purposes by assigning a score between 0 and $100 \%$. For our study, the type and degree of emphysema were reassessed by an experienced $\mathrm{NCOH}$ pathologist who was blind to the men's smoking or dust exposure history and the purpose of the study. The grid method with 20 radiating zones was used. Each zone was assigned scores for centriacinar (CAE) and panacinar (PAE) type of emphysema in such a way that the sum of the two scores in each zone ranged from 0 to 5 . The sum score over all 20 zones was calculated for CAE, PAE, and total emphysema (TE = CAE + PAE), and each was expressed as a percentage of 100 (or less than 100 if some zones were missing).

The emphysema scores in our study were categorised and compared with the original $\mathrm{NCOH}$ grades given as none $(<10 \%)$, insignificant (10-34\%), moderate (35-64\%), and marked ( $\geqslant 65 \%$ ) (table 1 ). The disagreement between none and insignificant degree is not as important as the agreement in that there were only two cases with a moderate degree of emphysema (with scores of $37 \%$ and $45 \%$ ). The disagreements on insignificant and moderate degree were for the cases with emphysema scores close to $35 \%$.

ASSESSMENT OF AIRWAY DISEASE AT NECROPSY The pathological assessment of airways disease is done on lungs that are already at varying stages of decomposition when preserved in formaldehyde. This compromises the assessment of the large airways disease, but even more so of the small airways disease, as only small loose pieces of bronchiolar epithelium can be seen. Nevertheless, a moderate 
degree of bronchitis or bronchiolitis, based on necropsy diagnosis of large and small airways disease, in addition to a given number of years of service in gold mines, is a sufficient criterion for compensation for COPD in South African gold miners.

Small airways disease is assessed mainly by goblet cell metaplasia in bronchioles (airways under $2 \mathrm{~mm}$ in diameter). It is graded, according to the ratio between the number of goblet cells and the total number of cells seen, as insignificant (up to 50\%), moderate $(50-75 \%)$, and marked ( $>75 \%)$. Large airways disease is assessed by mucus gland hyperplasia in a main bronchus. It is graded according to the ratio between mucus glands and total bronchial epithelium thickness, with the Reid Index, as insignificant $(<6)$, moderate $(6-7)$, and marked $(>7)$.

The repeatability of the diagnosis of goblet cell metaplasia and mucus gland hyperplasia, and of the assessment of the quality of the material, was tested on a sample of 24 subjects (of the 242) who had varying degrees of obstructive impairment of lung function. One experienced pathologist made the assessment independently twice. For mucus gland hyperplasia, the repeatability of the diagnosis was statistically significant (Spearman correlation coefficient $=0.70, p=0.0004)$. Even so, of the seven classified as moderate on the first reading (none was classified as marked), three were classified as insignificant on the second reading. The agreement on quality of the material for the assessment of mucus gland hyperplasia was relatively good, as 19 out of the 24 were classified as good on both readings; the rest were poor or unreadable. For goblet cell metaplasia, the repeatability was poor and the quality of the material was classified as good only in eight subjects on the first reading, and half of these were classified as poor on the second reading. The rest were classified as poor or unreadable. Because of the unreliability of the diagnosis of goblet cell metaplasia, only the presence and degree of mucus gland hyperplasia was used in a statistical analysis (two subjects were excluded as on the original $\mathrm{NCOH}$ reading the material was classified as poor).

\section{SILICOSIS AT NECROPSY}

The presence of silicosis is established for compensation purposes by a macroscopic and microscopic examination. The degree of silicosis in the lung parenchyma is based on the profusion of palpable islets in the lungs as fol-

Table 2 Distribution of study subjects according to number of lung function tests done at $M B O D$

\begin{tabular}{lllllll}
\hline $\begin{array}{l}\text { No of } \\
\text { tests }\end{array}$ & $\begin{array}{l}\text { No } \\
\text { of } \\
\text { subjects }\end{array}$ & $\begin{array}{l}\text { Age at first } \\
\text { test } \\
\text { Mean (range) }\end{array}$ & $\begin{array}{l}\text { Age at last } \\
\text { test } \\
\text { Mean (range) }\end{array}$ & $\begin{array}{l}\text { Age at death } \\
\text { Mean (range) }\end{array}$ & $\begin{array}{l}\text { Years of } \\
\text { mining } \\
\text { Mean }\end{array}$ & $\begin{array}{l}\text { CDI } \\
\text { Mean }\end{array}$ \\
\hline 0 & 68 & & & $63(46-92)$ & 18 & $20 \cdot 5$ \\
1 & 57 & $58(33-76)$ & & $66(45-84)$ & 21 & $27 \cdot 4$ \\
2 & 34 & $57(38-67)$ & $62(49-70)$ & $67(49-85)$ & 24 & $34 \cdot 8$ \\
3 & 23 & $56(45-71)$ & $65(57-75)$ & $68(60-77)$ & 26 & $40 \cdot 1$ \\
4 & 13 & $55(45-72)$ & $64(56-75)$ & $68(62-78)$ & 26 & $38 \cdot 0$ \\
5 & 15 & $56(45-67)$ & $67(59-75)$ & $70(59-86)$ & 30 & $45 \cdot 2$ \\
6 & 32 & $53(41-72)$ & $66(50-81)$ & $68(51-82)$ & 29 & $47 \cdot 3$ \\
Total & 242 & & & & &
\end{tabular}

lows: none (0), insignificant $(<5)$, slight $(5-9)$, moderate (10-29), and marked $(\geqslant 30)$. Where there is massive fibrosis (confluent islets measuring $>2.0 \mathrm{~cm}$ in diameter) this is categorised as marked. The microscopic examination of histological slides is used to confirm that the nodules are silicotic. The degree of fibrosis in the lymph nodes is graded as some are fibrosed, are fibrosed and densely fibrosed. The degree of silicosis of the lung parenchyma and pleura and the degree of fibrosis in the lymph nodes are recorded in the PATHAUT file. The assessment of the presence of silicosis is considered generally to be reliable. In the 242 miners the degree of silicosis was as follows: 123 had none, 61 had an insignificant, 32 had a slight, 17 had a moderate, and nine had a marked degree of silicosis of the lung. There were 68 and 63 miners with a moderate and marked degree of lymph nodule fibrosis respectively.

\section{ASSESSMENT OF CHRONIC FUNCTIONAL} AIRFLOW IMPAIRMENT

Of the 242 miners, 174 miners had lung function tests done at MBOD. Only miners who request disability compensation, or who seek examination for health reasons, have lung function tests done. Table 2 shows the distribution of the 242 miners according to the number of lung function tests they had done at MBOD, their average age at the first and most recent test, years of gold mining, and cumulative dust exposure. The miners who did not have any tests were on average younger at death and had significantly lower dust exposure in comparison with the others. Several factors are involved in the selection process for having lung function tests, but a white miner with clinical signs of impairment is more likely to have tests than a miner with shorter exposure who feels healthy.

The highest forced expiratory volume in one second $\left(F E V_{1}\right)$, forced vital capacity (FVC), and slow vital capacity (VC) (selected from spirogram or flow-volume curve), as well as height and weight, were coded from each lung function test recorded in the miner's MBOD medical file. Based on results of lung function tests miners are categorised, at the time of testing, as normal, mild obstructive, moderate obstructive, marked obstructive, and restrictive depending on whether their lung function measurements fall within the lower $90 \%$ confidence interval $(90 \% \mathrm{CI})$ of the predicted value, within the $90 \%$ and $95 \%$ CI, within the $95 \%$ and $99 \% \mathrm{CI}$, and above the $99 \% \mathrm{CI}$ respectively. If a miner is categorised in the obstructive category, further tests are made to ascertain whether the airflow reduction is reversible after inhalation of bronchodilator or in time, to exclude asthma or other reasons for the abnormal tests. The final diagnosis is recorded with the tests and was used in our study to identify miners with impairment of lung function.

\section{SILICA DUST EXPOSURE}

Exposure to mining dust was coded for each miner from the official service records in 
Table 3 Characteristics of the 242 miners

\begin{tabular}{lll}
\hline Characteristics & Mean $(S D)$ & (range) \\
\hline Year of birth & $1915(9 \cdot 4)$ & $(1890-1940)$ \\
Year of death & $1981(3 \cdot 8)$ & $(1975-1989)$ \\
Age at death & $65 \cdot 9(8 \cdot 6)$ & $(45-92)$ \\
Years of mining & $23 \cdot 1(11 \cdot 0)$ & $(1-48)$ \\
First year in dust in mines & $1940(9 \cdot 9)$ & $(1909-1974)$ \\
Last year in dust in mines & $1970(9 \cdot 5)$ & $(1939-1988)$ \\
Cumulative dust $\left(\mathrm{mg} / \mathrm{m}^{3}\right.$-years) & $6 \cdot 8(2 \cdot 4)$ & $(0 \cdot 5-20 \cdot 2)$ \\
\hline
\end{tabular}

terms of the number of shifts worked in each occupation in a mine. A cumulative dust exposure in $\mathrm{mg} / \mathrm{m}^{3}$-years was calculated as a sum of products of the number of shifts spent in an occupational category and intensity of dust exposure in that category as estimated by Beadle $^{9}$ (for details see Hnizdo and SluisCremer $^{10}$ ). This measure of dust is strongly related to risk of silicosis. ${ }^{10}$

\section{STATISTICAL ANALYSIS}

As the emphysema scores were not normally distributed, non-parametric as well as parametric tests were applied for comparisons. To identify factors associated with lung function tests, degree of emphysema, and degree of mucus gland hyperplasia, the multiple linear regression model and the stepwise method of variable selection were applied.

\section{Results}

Table 3 shows the characteristics of the miners. On average, the miners were 65.9 years of age at death and had 23 (range 1-48) years of net gold mining service during 1940-70.

\section{EMPHYSEMA AND RELATED FACTORS}

Mainly, an insignificant degree of panacinar emphysema type was found. The figure shows the distribution of emphysema scores for the total, centriacinar, and panacinar emphysema types. The median emphysema score for total emphysema was 5 (range, 0-45\%). Only four subjects were classified as having a moderate

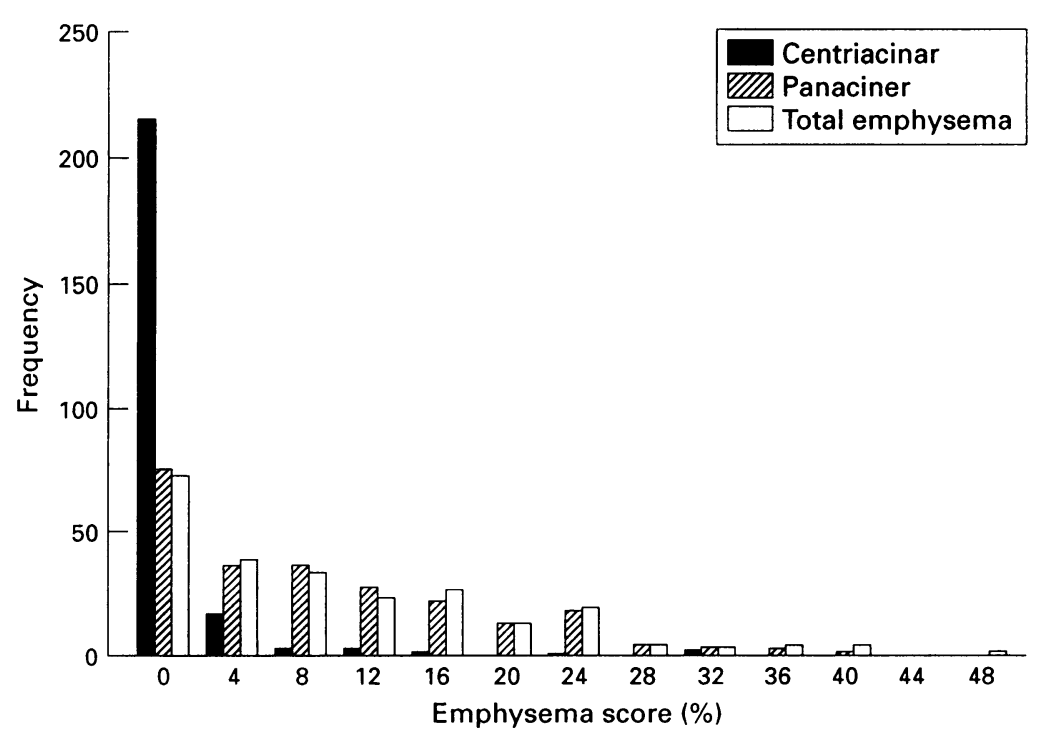

Frequency distribution for the centriacinar, panacinar, and total emyphysema type scores for non-smokers. degree of emphysema (score 35-65\%). Of these, two had normal lung function tests $\left(\mathrm{FEV}_{1} \%>70\right)$, one miner had an $\mathrm{FEV}_{1} \%$ of 51 , but had coronary heart disease, and one miner, who had only one year of underground service, was 87 years old at death and had pulmonary tuberculosis. When included in the multiple regression as an independent variable, the degree of emphysema was not selected as a predictor of the most recent lung function measurements $(p<0.15)$ when other confounding factors were adjusted for (table 4). Neither was the degree of emphysema associated with years of gold mining, cumulative dust index, or parenchymal silicosis when age at death was adjusted for. The degree of panacinar emphysema, however, was found to be associated with the degree of hilar gland nodules $(p<0.05)$. When age at death and year of birth were adjusted for, the mean emphysema scores (SE) increased with increasing degree of hilar gland fibrosis as $5 \cdot 2$ (1.03) for none, $7.2(1.30)$ for insignificant, $8.2(1.01)$ for moderate, and $9.05(1.09)$ for marked degree. The differences between the mean emphysema scores for moderate and marked categories and the lowest category were statistically significant $(\mathrm{p}<0.05)$.

\section{BRONCHITIS DIAGNOSED AT NECROPSY}

Of the 240 subjects in whom the diagnosis of mucus gland hyperplasia was done, $27(11 \%)$ had a moderate and none had a marked degree. In the multiple regression analysis, when the degree of mucus gland hyperplasia was entered as a response variable, the explanatory variables positively associated were age at death $(p=0.03)$ and body mass index (BMI; weight $(\mathrm{kg}) / \mathrm{height}(\mathrm{m})^{2} ; \quad \mathrm{p}=$ $0 \cdot 08)$. The degree of silicosis of the lung parenchyma was negatively associated $(p=$ $0 \cdot 005)$. Silica dust was not selected into the regression model.

\section{LUNG FUNCTION TESTS}

Table 4 shows the factors associated with the most recent lung function measurements (at $\mathrm{p}<0 \cdot 15)$. The factors not selected into the regression model were silicosis of the pleura and hilar glands nodules, years of gold mining, and cumulative dust exposure. The degree of bronchitis was the second most important predictor of $\mathrm{FEV}_{1}$ and FVC after age at test, then came height, silicosis of the lung, and BMI. The BMI and height were not related to $\mathrm{FEV}_{1} \%$. None of the dust exposure variables were selected into the model, even when silicosis was not considered. This may be due to the selection process, by which the miners with low dust exposure were excluded from lung function testing, resulting in reduced variation in the dust exposure variable. The degree of emphysema was not related to any of the tests.

There were 73 miners whose $\mathrm{FEV}_{1} / \mathrm{FVC}$ ratio was at some time less than $0 \cdot 70$. Medical files of these miners were examined independently by a specialist physician (GKS-C) and a physician experienced in interpretation of 
Table 4 Factors associated with lung function test values $(n=174)$ : regression coefficients (SE)

\begin{tabular}{|c|c|c|c|}
\hline \multirow[b]{2}{*}{ Factor } & \multicolumn{3}{|l|}{ Lung function test } \\
\hline & $F E V_{l}(l)$ & $F V C(I)$ & $F E V_{l} / F V C \%$ \\
\hline $\begin{array}{l}\text { Age at test } \\
\text { Mucus gland hyperplasia } \\
\text { Height }(\mathrm{cm}) \\
\text { Lung silicosis } \\
\text { Body mass index }\end{array}$ & $\begin{array}{l}-0.022(0.007)^{\star \star \star} \\
-0.279(0.077)^{\star \star \star} \\
0.030(0.008)^{\star \star} \\
-0.102(0.041)^{\star} \\
-0.025(0.011)^{\star}\end{array}$ & $\begin{array}{l}-0.021(0.007)^{\star \star \star} \\
-0.223(0.079)^{\star \star \star} \\
0.048(0.008)^{\star \star \star} \\
-0.092(0.047) \\
-0.031(0.011)^{\star}\end{array}$ & $\begin{array}{l}-0.166(0.113) \\
-3.110(1.281)^{\star \star} \\
-1.833(0.683)^{\star}\end{array}$ \\
\hline
\end{tabular}

pulmonary function (EB) to select miners with an appreciable degree of airflow limitation. According to a physician's report on the last medical examination, $43 \%$ of the miners were obese, $62 \%$ had high blood pressure, and $56 \%$ had heart disease in life. In 17 of the 73 miners, the comment on the lung function test indicated an obstructive or restrictive pattern. The medical records of these men were extracted and table 5 summarises selected medical diagnoses made in life, and at necropsy. It is noteworthy that the necropsy findings for COPD, - namely, emphysema score, mucus gland hyperplasia, and goblet cell metaplasia, do not indicate substantial pathological changes consistent with COPD in most of these men. Also in life, only one miner (No 12) had clinical evidence of chronic obstructive lung disease. There were six miners who had a history of chronic bronchitis in life; however, the necropsy findings for mucus gland hyperplasia and goblet cell metaplasia do not reflect this condition (this may also be due to unreliability of these two necropsy findings). Of the six men with a diagnosed restrictive pattern, five were shown to have some degree of silicosis at necropsy. Obesity and heart disease were diagnosed in 10 of these men. In comparison with the rest of the miners, the 17 miners had significantly higher cumulative dust exposure up to 35 years of age $\left(3.5 \vee 2.2 \mathrm{mg} / \mathrm{m}^{3}\right.$-years, $\mathrm{p}<$ 0.0007 ), from 35 to 45 years of age ( $3.1 v 1.9$ $\mathrm{mg} / \mathrm{m}^{3}$-years, $\mathrm{p}<0.0002$ ), and total cumulative dust up to death $\left(10.4 v 6.6 \mathrm{mg} / \mathrm{m}^{3}\right.$-years, $\mathrm{p}<0.0001$ ).

\section{Discussion}

In this study of lifelong non-smokers exposed to silica dust, only an insignificant degree of predominantly panacinar emphysema was found. Silica dust exposure or parenchymal silicosis were not related to the degree of emphysema. The degree of panacinar emphysema, however, was related to the degree of fibrosis in hilar glands, which could have acted as a surrogate for exposure to silica dust. The degree of emphysema was not found to be a significant predictor of the most recent lung function tests (table 4 ). Thus the results indicate that the amount of emphysema found in lifelong non-smokers exposed for many years to silica dust is unlikely to cause a moderate degree of airflow limitation. In smokers, however, the association between silica dust and the degree of emphysema was statistically significant, suggesting that tobacco smoking potentiates the effect of silica dust. ${ }^{6}$ A considerable amount of lung destruction has to occur, however, before macroscopic emphysema becomes identifiable.

The necropsy material used in the present study was not suitable for a diagnosis of thickening and fibrosis of small airways which, it has been suggested, is caused by silica dust exposure and associated with a significant loss of lung function. ${ }^{12}$ Nevertheless, it was the intention of this study to identify miners classified by lung function tests as having moderate airflow limitation. Because the degree of emphysema was known, it was hoped that one could deduce indirectly whether airway disease or emphysema was responsible for the obstructive pattern. On examination of the medical files of the 73 miners whose $\mathrm{FEV}_{1} / \mathrm{FVC}$ ratios were less than $0 \cdot 70$, it was found that obesity and general lack of fitness could also have contributed to the airflow limitation. ${ }^{11}$ Table 5 summarises the clinical and necropsy findings for the 17 miners whose medical files indicated the presence of some impairment of lung function. Of the six men with a restrictive pattern, five had some degree of silicosis at necropsy. Emphysema

Table 5 Comparison of medical findings in life and at necropsy in 17 South African gold miners diagnosed as having respiratory impairment in life

\begin{tabular}{|c|c|c|c|c|c|c|c|c|c|c|c|}
\hline \multirow[b]{3}{*}{$\begin{array}{l}\text { Case } \\
\text { No }\end{array}$} & \multirow{2}{*}{\multicolumn{5}{|c|}{ Findings in life }} & \multicolumn{6}{|c|}{ Findings at necropsy } \\
\hline & & & & & & \multicolumn{3}{|l|}{ Silicosis } & \multirow[b]{2}{*}{$\begin{array}{l}\text { Emphysema } \\
\text { score (\%) }\end{array}$} & \multirow[b]{2}{*}{ Bronchitis } & \multirow[b]{2}{*}{ Bronchiolitis } \\
\hline & $F E V_{1}(\%)$ & $\begin{array}{l}\text { Functional } \\
\text { pattern }\end{array}$ & Bronchitis & $\begin{array}{l}x \text { Ray film } \\
\text { changes }\end{array}$ & Others & Lung & Hilar & Pleura & & & \\
\hline 1 & 62 & Restr & No ev & Other fibrosis & HD & None & Mod & None & 31 & Insig & Insig \\
\hline 2 & 77 & Restr & No ev & Silicosis & & Mod & Mod & None & 0 & None & Insig \\
\hline 3 & 62 & Restr & History & Normal & HD & Slight & Mod & Mod & 0 & Insig & Insig \\
\hline 4 & 53 & Restr & No ev & Silicosis & HD, obese & Insig & Slight & Insig & 4 & Mod & Mod \\
\hline 5 & 73 & Obstr & No ev & Pleural & & Insig & Insig & Insig & 9 & Mod & Mod \\
\hline 7 & 49 & Obstr & No ev & Silicosis & HD & Mod & Slight & Slight & 21 & None & None \\
\hline 8 & 64 & Obstr & No ev & Normal & HD, obese & Insig & Mod & Insig & 6 & Insig & Insig \\
\hline 9 & 86 & Restr & Mild & Silicosis & & Marked & Mod & None & 19 & None & None \\
\hline 10 & 63 & Obstr & Mild & Normal & Obese & None & Slight & None & 23 & None & Insig \\
\hline 11 & 66 & Obstr & No ev & Oth path & HBP & Insig & Slight & None & 0 & Insig & None \\
\hline 12 & 50 & Obstr & COPD & Normal & HD, obese & None & Slight & Insig & 3 & Insig & Mod \\
\hline 13 & 70 & Obstr & No ev & Normal & HD, obese & Insig & Slight & None & 17 & None & None \\
\hline 14 & 56 & Restr & History & Silicosis & HD,HBP & Marked & Mod & Marked & 6 & None & None \\
\hline 15 & 83 & Obstr & No ev & Normal & Obese & None & Insig & None & 17 & None & Insig \\
\hline 16 & 78 & Obstr & Mild & Normal & HBP & None & None & None & 8 & Mod & Insig \\
\hline 17 & 70 & Obstr & Mild & Normal & HD, obese & None & Slight & None & 19 & Insig & None \\
\hline
\end{tabular}


score was insignificant and the diagnosis of mucus gland hyperplasia and goblet cell metaplasia did not correspond with a history of bronchitis in life. The medical records were consistent with mild bronchitis in those diagnosed to have bronchitis in life. Thus these results indicate that silicosis, heart disease, and obesity are pathological factors that may play a part in the impairment of lung function in this group of miners. Whether small airway disease is a factor in the loss of lung function in this group cannot be resolved by this study.

It has been estimated that a career gold miner who never smokes loses on average around $250 \mathrm{ml}$ or more of $\mathrm{FEV}_{1}{ }^{8}$ by 50 years of age due to the effect of silica dust, ${ }^{48}$ and thus there should be some significant morphological changes in the lung due to the effect of inhalation of silica dust. The factors selected as being negatively related to the lung function tests were age, mucus gland hyperplasia, silicosis of the lung, and BMI (table 4). The degree of emphysema was not selected. The average $\mathrm{BMI}$ in miners in our study was 28.8 . Obesity was shown in other studies to be associated with a peripheral airways disease. ${ }^{11}$ Silicosis was a significant predictor of FEV and $\mathrm{FEV}_{1} / \mathrm{FVC}$ ratio, which suggests that silicosis is associated with an obstructive pattern, but according to the diagnosis on the lung function tests of the 17 miners shown in table 5 , a restrictive pattern also occurs in silicotic workers.

The association between silicosis and loss of $\mathrm{FEV}_{1}$ was seen in another group of white gold miners who never smoked and in black gold miners who had low tobacco consumption. ${ }^{48}$ On the other hand, a case-control study, specifically designed to assess the effect of silicosis on lung function and using 61 gold miners with radiological silicosis and 61 controls matched for age, dust exposure and smoking habits did not find significant differences between the two groups for a full range of lung function tests. ${ }^{12}$ The exceptions were the slope of the alveolar plateau (phase 3 ) and the closing volume, for which the silicotic workers had significantly higher values. In that study only eight pairs were non-smokers.

It is not certain how parenchymal silicosis could increase airflow obstruction. As parenchymal silicosis and emphysema were unrelated, silicotic nodules are unlikely to act as a surrogate for emphysema. It is possible, however, that silicotic nodules act as a surrogate for fibrosis of airways walls as in other studies, fibrosis of airway walls was a pathological feature associated with exposure to silica dust. ${ }^{2}$ As radiological silicosis does not seem to be a predictor of loss of lung function in smokers, ${ }^{8}$ this effect is likely to be smaller than the effect of smoking or the synergistic effect of dust and smoking on airflow limitation, which are known to be associated with emphysema. $^{6}$

An additional purpose of the study was to establish whether the diagnosis for bronchitis, based on mucus gland hyperplasia, and of bronchiolitis, based on goblet cell metaplasia, as done at necropsy on the gold miners at $\mathrm{NCOH}$, reflect on impairment of lung function associated with exposure to silica dust. The results from this study provide no evidence for this. Although the degree of mucus gland hyperplasia was associated with a significant reduction in $\mathrm{FEV}_{1}, \mathrm{FVC}$, and $\mathrm{FEV}_{1} \%$, it was itself negatively associated with the degree of silicosis of the lung $(p=0.005)$, and positively with age at death and with BMI, and was not associated with dust exposure. Thus for an individual case, a positive diagnosis of mucus gland hyperplasia or goblet cell metaplasia at necropsy did not seem to be a reliable indicator of impairment of lung function or a history of chronic bronchitis, as many miners with a moderate degree of gland hyperplasia had normal lung function tests and did not have a history of chronic bronchitis.

The quality of the histological material for the diagnosis of bronchiolitis, with goblet cell metaplasia as a criterion, was mostly poor or unreadable in a sample of 24 miners selected for a repeatability study. It is therefore questionable whether the necropsy diagnosis of bronchiolitis based on this criteria is a correct and reliable criterion for compensation for COPD as it is used for South African gold miners.

The limiting factors in the present study were the quality of smoking data for selection of a sufficient number of non-smokers, the quality of the histological material for the diagnosis of the peripheral airway disease, the fact that not all the miners had lung function tests done, the confounding effect of heart disease and obesity, and the fact that the degree of in life compensation reflects to some extent on the necropsy rate of the gold miners. The quality of the material reflects the difficulty of the subject being studied.

Accepting these limitations, the study indicates, both directly and indirectly, that the important preventive measures for respiratory health of gold miners are low respirable dust levels for prevention of silicosis and reduction of tobacco smoking for prevention of emphysema.

We thank Dr Goldstein from NCOH for evaluation of the histological slides for bronchitis and bronchiolitis and Colleen Summerson for extracting and preparing the data.

1 Churg A, Hobson J, Wright J. Functional and morphological comparison in silica- and elastase-induced airflow obstruction. Exp Lung Res 1989;15:813-22.

2 Churg A, Wright J, Wiggs B, Pare PD, Lazar N. Small airways disease and mineral dust exposure. Am Rev airways disease and minera

3 Wiles FJ, Faure MH. Chronic obstructive lung disease in goldminers. In: Walton WH, ed. Inhaled particles IV, par 2. Oxford: Pergamon Press, 1977:727-35.

4 Cowie RL, Mabena SK. Silicosis, chronic airflow limitation, and chronic bronchitis in South African gold miners. Am Rev Respir Dis 1991;143:80-4.

5 Becklake MR, Irwig L, Kielkowski D, Webster I, De Bee $M$, Landau S. The predictors of emphysema in South African goldminers. Am Rev Respir Dis 1987;135: $1234-41$

6 Hnizdo E, Sluis-Cremer GK, Abramowitz JA. Emphysema type in relation to silica dust exposure, in South African goldminers. Am Rev Respir Dis 1991;143:1241-7.

7 American Thoracic Society. Standards for the diagnosis 
and care of patients with chronic obstructive pulmonary disease (COPD) and asthma. Am Rev Respir Dis 1987; 136:225-43.

8 Hnizdo E. Loss of lung function associated with silica dust exposure and with tobacco smoking in South African exposure and with tobacco smoking in South

9 Beadle DG. The relationship between the amount of dust breathed and the development of radiological signs of silicosis: an epidemiological study of South African gold miners. In: Walton WH, ed. Inhaled particles III. Oxford:
Pergamon Press, 1971:953-64.

10 Hnizdo Eva, Sluis-Cremer GK. Risk of silicosis in a cohort of white South African gold miners. Am 7 Ind Med 1993;24:447-57.

11 Weiss ST. Pulmonary function as a phenotype physiological marker of cardiovascular morbidity and mortality [editorial]. Chest 1991;99:265-6.

12 Wiles FJ, Baskind E, Hessel PA, Bezuidenhout B, Hnizdo E. Lung function in silicosis. Int Arch Occup Environ Health 1992;63:387-91.

\section{Vancouver style}

All manuscripts submitted to Occup Environ Med should conform to the uniform requirements for manuscripts submitted to biomedical journals (known as the Vancouver style.)

Occup Environ Med, together with many other international biomedical journals, has agreed to accept articles prepared in accordance with the Vancouver style. The style (described in full in the $B M F, 24$ February $1979, \mathrm{p} \mathrm{532}$ ) is intended to standardise requirements for authors.

References should be numbered consecutively in the order in which they are first mentioned in the text by Arabic numerals above the line on each occasion the reference is cited (Manson ${ }^{1}$ confirmed other reports $^{2-5}$. . .). In future references to papers submitted to Occup Environ Med should include: the names of all authors if there are seven or less or, if there are more, the first six followed by et al; the title of journal articles or book chapters; the titles of journals abbreviated according to the style of Index Medicus; and the first and final page numbers of the article or chapter. Titles not in Index Medicus should be given in full.

Examples of common forms of references are:

1 International Steering Committee of Medical Editors, Uniform requirements for manuscripts submitted to biomedical journals. $\mathrm{Br} M e d$ f 1979;1:532-5.

2 Soter NA, Wasserman SI, Austen KF. Cold urticaria: release into the circulation of histamine and eosinophil chemotactic factor of anaphylaxis during cold challenge. $N$ Engl $\mathcal{F}$ Med 1976;294:687-90.

3 Weinstein L, Swartz MN. Pathogenic properties of invading micro-organisms. In: Sodeman WA Jr, Sodem WA of disease. Philadelphia: W B Saunders, 1974:457-72. 